\title{
Review Paper on Properties of Concrete of by Partial Replacement of Sand and Cement with Copper Slag and Rice Ask Ash
}

\author{
Agnimesh Singh Tomar' ${ }^{1}$, Pratiksha Malviya ${ }^{2}$ \\ ${ }^{1} \mathrm{M}$. Tech. Scholar, ${ }^{2}$ Professor \\ 1,2Department of Civil Engineering, Millennium Institute of Technology \& Science \\ 1,2Bhopal, Madhya Pradesh, India
}

\section{INTRODUCTION}

The value of concrete in present society cannot be underestimated. We can see concrete structures everywhere, such as buildings, roads, bridges, and dams. There is no escaping the impact concrete makes on your everyday life. Concrete is a composite material which is made up of filler and a binder. Typical concrete is a mixture of fine aggregate (sand), coarse aggregate (rock), cement, and water. Cement and lime are usually used as binding materials, while the sand binder is mixed as fine aggregates and crushed stones, gravel, broken bricks; clinker is employed as coarse aggregates. The concrete having cement, sand and coarse aggregates mix up in an appropriate percentage in addition to water is called cement concrete. In this kind of concrete, cement is used as a binding substance, sand as fine aggregates and gravel, crushed stones as coarse aggregates.

\section{Literature Survey}

1. Sukhoon Pyo, Sherif El-Tawil, Antoine E. Naaman, "Direct tensile behavior of ultra high performance fiber reinforced concrete (UHP-FRC) at high strain rates", Elsevier 2016.

Conducted analysis using a recently developed impact testing system that uses suddenly released strain energy to generate an impact pulse. Three fiber types were considered, a twisted fiber and two other types of straight fibers. Specimen impact response was evaluated in terms of first cracking strength, post-cracking strength, energy absorption capacity and strain capacity. The test results indicate that specimens with twisted fibers generally exhibit somewhat better mechanical properties than specimens with straight fibers for the range of strain rates considered. All Ultra-High Performance Fiber Reinforced Concrete (UHP-FRC) series tested showed exceptional rate sensitivities in energy absorption capacity, generally becoming much more energy dissipative under increasing strain rates. This characteristic highlights the potential of Ultra-High Performance Fiber Reinforced Concrete (UHP-FRC) as promising cement based material for impact- and blast-resistant applications.

2. Yuh-Shiou Tai, Sherif El-Tawil, Ta-Hsiang Chung, "Performance of deformed steel fibers embedded in ultrahigh performance concrete subjected to various pullout rates" ,Elsevier 2016

Investigated the mechanical behavior of high performance steel fibers embedded in Ultra-high performance concrete (UHPC) at various pullout speeds the test variables were steel fiber type, matrix constituents, and pullout rates. In particular, five types of high strength steel fiber were used and five pullout rates from quasi-static to impact rates were applied. In addition, the effect of reduced amount of glass powder, as key matrix constituent, on pullout behavior was explored. Experimental results show that the pullout response of all of the fiber types exhibit progressively increasing rate sensitivity as the pullout speed increases and becomes significant during impact loading. It is most pominent in the smooth and twisted fibers and least in the hooked fibers. Additionally, scanning electron microscope studies are presented and used to explain the mechanism of rate enhancement from a microscopic perspective.

3. Anju Ramesan, Shemy S. Babu, Aswathy Lal, "Performance of light weight concrete with plastic aggregate", International Journal of Engineering Research and Applications, Vol.5, Issue 8, August 2015, pp.105-110.

Studied about suitability of performance of light weight concrete with plastic aggregate. the suitability of recycled plastics (high density polyethylene) as coarse aggregate in concrete by conducting various tests like workability by slump test, compressive strength of cube and cylinder, splitting tensile strength test of cylinder, flexural strength of R.C.C as well as P.C.C Beams, to determine the property and behavior in concrete. Effect of replacement of coarse aggregate with various percentages of plastic aggregate on behavior of concrete was experimentally investigated and the optimum replacement of coarse aggregate was found out. The results showed that the addition of plastic aggregate to the concrete mixture improved the properties of the resultant mix.

4. Sahil Verma, Sahil Arora, "Replacement of Natural Sand in Concrete by Polyethylene Bottles" International Research Journal of Engineering and Technology (IRJET), Volume: 02 Issue: 01, Apr-2015.

Investigated about the use the waste plastic crushed bottles of appropriate size in concrete with partial replacement of fine aggregates and it has the potential of disposing of large quantities of the catastrophic waste in a beneficial way. The environmental effects can be substantially reduced by proper encapsulation of these waste plastic bottles. The study also gives the comparison of compressive strength of normal conventional concrete with the concrete made from the partial substitution of aggregates with Polyethylene 
Terephthalate bottles. Hence concrete with waste Polyethylene Terephthalate (PET) fiber can be used as an effective plastic waste management practice in future.

5. Binaya Patnaik, Seshadri Sekhar. T, Srinivasa Rao, "Strength and Durability Properties Of Copper Slag Admixed Concrete" International Journal of Research in Engineering and Technology, e- ISSN: 2319-1163, p-ISSN: 2321-7308, Volume 4, Issue 1, Feb 2015

Sudied about the strength and durability properties of concrete having copper slag as a partial replacement of sand (fine aggregate) and results have been presented in this paper. Two different kinds of Concrete Grade (M20 \& M30) were used with different proportions of copper slag replacement i.e 0 to $50 \%$ in the concrete. Strength \& Durability properties such as compressive strength, Split Tensile Strength, flexural strength, acid resistivity and sulphate resistivity were evaluated for both mixes of concrete. Test results explains that the strength properties of concrete has better having copper slag as a partial substitute of Sand (up to 40\%) in concrete but in terms of stability the concrete found to be low resistant to acid attack and better resistance against sulphate attack.

6. Binaya Patnaik, Seshadri Sekhar. T, Srinivasa Rao, "Strength and Durability Properties of concrete mix. For M 20 and M 25 grade concrete, the optimum sand exchange proportion is generally $20-25 \%$. Moreover, generally the sand can be replaced till $30-40 \%$ by sand in material. The exchanging of sand by foundry sand in concrete increases the compressive force, split tensile force, flexure power and modulus of flexibility. Usually the experimental analysis is carried out for concrete grade. Further investigation should be find out regarding M 35 and M 40 grade concrete, which could be useful for multi-storey buildings, construction of bridges, expressways, etc. where strength requirement is high.

7. Pranshu Saxena, Ashish Simalti, "Scope of Replacing Fine Aggregate With Copper Slag In Concrete" International Journal of Technical Research and Applications, e-ISSN: 2320-8163, Volume 3, Issue 4, August 2015, PP. 44-48.

Sudied about scope of replacement of fine aggregate from copper slag in concrete. Copper slag represents a popular alternative to sand as a blasting medium in industrial cleaning. Using blasting or high-pressure spraying techniques, companies are using copper slag to clean large smelting equipment or furnaces. Material like copper slag can be used as one which can reduce the cost of construction. Their attempt has been made to compile the various studies done on the replacement of copper slag in fine aggregate to judge the strength of concrete.

8. M. A. Rasheed, S. Suriya Prakash, "mechanical behavior of sustainable hybrid-synthetic fiber reinforced cellular light weight concrete for structural applications of masonry", Elsevier, 2015.

Investigated to develop a high performance fiber reinforced cellular concrete to provide a better alternative than aerated autoclaved concrete blocks for structural applications of masonry. Use of micro-fibers (fibrillated) enhances precracking behavior of masonry by arresting cracks at microscale, while macro (structural) fibers induce ductile behavior in post-peak region by arresting the crack propagation soon after the crack initiation. In particular, the mechanical behavior of Cellular light weight concrete (CLC) cylinders under pure compression and Cellular light weight concrete (CLC) blocks under flexure with and without polyolefin structural fiber reinforcement as well as hybrid fiber reinforcement is investigated. Test results indicate that the addition of structural fibers improved the compressive strength up to $66.8 \%$ for $0.55 \%$ volume fraction. Hybrid fiber reinforcement enhanced the peak strength and ductility which indicated better crack bridging both at micro and macro levels.

9. S. W. Tang, Y. Yao, C. Andrade, Z. J. Li, "Recent durability studies on concrete structure”, Elsevier, 2015.

recent research activities on the durability of concrete, including major durability problems such as alkali aggregate reaction, sulphate attack, steel corrosion and freeze- thaw also analyzed durability of concrete in marine environment and coupling effects of mechanical load and environmental factors on durability of concrete. The study of natural green inhibitor for steel corrosion also opens a promising research direction in the near future. With respect to durability design codes, the mainstream codes or methods have more or less intrinsic drawbacks due to the failure to comprehensively consider various coupling effects of mechanical loading and multi environmental impacts. Therefore, it is necessary to develop a new approach of unified load-carrying capability and durability service life design theory for more accurate service life estimate.

10. M. C. G. Juenger, Rafat Siddique, "Recent advances in understanding the role of supplementary cementitious materials in concrete", Elsevier 2015.

Studied about use of supplementary cementitious materials in concrete. Supplementary cementitious materials (SCMs) are commonly used in concrete mixtures as a replacement of a portion of clinker in cement or as a replacement of a portion of cement in concrete. This study is favorable to the industry, generally resulting in concrete with lower cost, lower environmental impact, higher long-term strength, and improved long- term durability. SCMs have been used in Portland cement concrete for decades and many of their effects are well-understood. Most recent research on SCMs has focused on a few areas: exploring new materials, increasing replacement amounts, developing better test methods, treating or modifying materials, and using additives for e.g limestone or nano silica to improve performance. The advances in knowledge provided by research in these areas are reviewed in this paper, emphasizing the impact of the research on the field.

11. Tomas U. Ganiron, "Effect of Thermoplastic as Fine Aggregate to Concrete Mixture", International Journal of Advanced Science and Technology, Volume 62, pp.31-42, 2014.

Studied about the effects of thermoplastic when added to concrete cement and needs of the ecological sector in terms of recycling the waste plastic that harms not only the soil structure and the environment The plastic was grounded into pieces for concrete mixture, where it substitutes the $5 \%$ of the fine aggregate, which is the sand. It then undergoes to strength test that investigate whether it can pass or at least equal the standard specification of concrete mix for wall panel. The experimentation went through moisture content test, specific gravity test, slump test, sieve analysis, compressive test and flexural test. 
12. A. O. Olanike, "A Comparative Analysis of Modulus of Rupture and Splitting Tensile Strength of Recycled Aggregate Concrete", American Journal of Engineering Research e-ISSN: 2320-0847, Volume-03, Issue- 02, pp-141-147, 2014.

Conducted the comparative analysis of the modulus of rupture and the splitting tensile strength of recycled aggregate concrete. The two properties are usually used to estimate the tensile strength of concrete; however, they do not usually yield the same results hence need to investigate each of the properties. Taguchi optimization technique was employed to reduce the number of trials needed to get the results. The results showed that the splitting tensile strength ranges between $60-80 \%$ of the modulus of rupture which is also known as the flexural strength.

13. K. Wille, S. El-Tawil, A. E. Naaman, "Properties of strain hardening ultra high performance fiber reinforced concrete (UHP-FRC) under direct tensile loading", Elsevier, 2014.

Investigate and analyze the uniaxial tensile behavior of the new material. The paper reviews and categorizes a variety of tensile test setups used by other researchers and presents a revised tensile set up tailored to obtain reliable results with minimal preparation effort. The experimental investigation considers three types of steel fibers, each in three different volume fractions. Elastic, strain hardening and softening tensile parameters, such as first cracking stress and strain, elastic and strain hardening modulus, composite strength and energy dissipation capacity, of the Ultra-High Performance Fiber Reinforced Concrete (UHP-FRC) are characterized, analyzed and linked to the crack pattern observed by microscopic analysis. Models are proposed for representing the tensile stress-strain response of the material.

14, Khalid Raza, Apoorv Singh, R. D. Patel, "Strength Analysis of Concrete by Using Iron Slag as A Partial Replacement of Normal Aggregate in Concrete", International Journal of Science and Research, ISSN: 2319-7064, Volume 3 Issue 10, October 2014.

Analyses the concrete performance by using iron slag as a partial replacement of coarse aggregates in concrete. In this study the coarse aggregate (CA) were partially replaced with iron slag aggregate at different proportions of $0 \%, 10 \%, 20 \%$, $30 \% 40 \%$ and $50 \%$. Compressive strength and flexural strength on M40 grade of concrete with $0.45 \mathrm{w}$-c ratio were investigated. In which to determine and check out the compressive strength, Flexural strength, and split tensile strength of concrete with various percentages of iron slag aggregate. The result has been found from the various tests which were compared with conventional concrete. Thus the use of iron slag in concrete could enhance the strength in concrete.

\section{Problem identification}

$>$ Natural resources are decreasing in all over the world and increasing wastes from industries generated simultaneously.

$>$ The eco-Friendly and reliable development for construction consists the use of non-conventional and different waste materials and recycling of waste material for reducing emissions in environments and decreasing the use of natural resources.

\section{Objectives}

The objectives of the research are outlined below:

$>$ To study the properties of fresh concrete and harden concrete prepared by replacement of copper slag and rice ask ash.

\section{CONCLUSION}

$>$ The utilization of copper slag in concrete provides additional environmental as well as technical benefits for all related industries. Partial replacement of copper slag in fine aggregate reduces the cost of making concrete.

\section{REFERENCES}

[1] A. O. Olanike, "A Comparative Analysis of Modulus of Rupture and Splitting Tensile Strength of Recycled Aggregate Concrete", American Journal of Engineering Research e-ISSN: 2320-0847, Volume-03, Issue-02, pp141-147, 2014.

[2] Anju Ramesan, Shemy S. Babu, Aswathy Lal, "Performance of light weight concrete with plastic aggregate", International Journal of Engineering Research and Applications, Vol. 5, Issue 8, August 2015, pp.105-110.

[3] Binaya Patnaik, Seshadri Sekhar. T, Srinivasa Rao, "Strength and Durability Properties Of Copper Slag Admixed Concrete" International Journal of Research in Engineering and Technology, e-ISSN: 2319-1163, pISSN: 2321-7308, Volume 4, Issue 1, Feb 2015.

[4] Chinmay buddhadev, Jayesh kumar pitroda, Prof. Chetna m. Vyas, "A review of innovative use of copper slag and foundry sand in design mix concrete" Journal Of International Academic Research For Multidisciplinary, Impact Factor 1.625, ISSN: 23205083, Volume 2, Issue 12, January 2015.

[5] Jeffrey W. Bullard, Hamlin M. Jennings, Richard A. Livingston, Andre Nonat, George W. Scherer, Jeffrey S. Schweitzer, Karen L. Scrivener, Jeffrey J. Thomas, "Mechanisms of cement hydration", Elsevier 2011.

[6] M. A. Rasheed, S. Suriya Prakash, "mechanical behavior of sustainable hybrid- synthetic fiber reinforced cellular light weight concrete for structural applications of masonry", Elsevier, 2015.

[7] M. C. G. Juenger, Rafat Siddique, "Recent advances in understanding the role of supplementary cementitious materials in concrete", Elsevier 2015.

[8] M. Etxeberria, E. Vázquez, A. Marí, M. Barra, "Influence of amount of recycled coarse aggregates and production process on properties of recycled aggregate concrete", Elsevier 2007.

[9] M. Chockalingam, D. Jayganesh, J. Vijayaraghavan, Dr. J. Jegan, "Scope for Reuse of Copper Slag in Concrete", International Journal of Civil Enigneering and Technology, e-ISSN: 0976-6316, Volume 4, Issue 6, 2013.

[10] P. F. Castro, A. Mendes Neto, "Assessing strength variability of concrete structural elements", 8th International Conference of the Slovenian Society for Non-Destructive Testing, Sep. 2005.

[11] Pranshu Saxena, Ashish Simalti, "Scope of Replacing Fine Aggregate With Copper Slag In Concrete" International Journal of Technical Research and Applications, e-ISSN: 2320-8163, Volume 3, Issue 4, August 2015, PP. 44-48. 